\title{
FEDERICO CASTELLÓN. UNA FIGURA RECUPERADA PARA EL ARTE ESPAÑOL
}

\section{FEDERICO CASTELLÓN. A FIGURE RECOVERED FOR SPANISH ART}

\author{
Federico Castellón Serrano \\ Universidad de Málaga \\ federicocastellon@gmail.com
}

Recibido: 02 abril 2020 Aceptado: 20 mayo 2020 Publicado: 01 julio 2020

\begin{abstract}
Resumen: La figura de Federico Castellón Martínez (Alhabia 1914-New York 1971) ha permanecido casi olvidada en España hasta hace muy poco tiempo, en contraste con su país de adopción, Estados Unidos, en el que fue un artista muy valorado desde su juventud. Afortunadamente cada vez son más los estudios y exposiciones sobre su obra en su país natal con los que se descubre la verdadera dimensión artística del almeriense.

Palabras clave: Federico Castellón, surrealismo, expresionismo, grabado, litografía

Abstract: The artist Federico Castellón Martínez (Alhabia, 1914-New York, 1971) has remained almost forgotten in Spain until recently, in contrast to his country of adoption, the United States, where he has been admired since his youth. Fortunately, with the increasing studies and exhibitions of his work in his native country, the true artistic dimensions of this Almerian are being discovered.
\end{abstract}

Keywords: Federico Castellon, surrealism, expressionism, engraving, lithography

\section{Introducción}

El 29 de julio de 1971 Federico Castellón fallecía en Nueva York víctima del rápido desarrollo de un cáncer. Atrás quedaba una trayectoria artística impresionante, con un amplio reconocimiento en los Estados Unidos, país que lo nombró miembro numerario de la Academia Americana de Artes y Letras y donde su obra forma parte de las colecciones de los más prestigiosos museos como el MOMA, además de muchos otros, sobre todo por su ingente obra gráfica, dispersa por todo el país. 
Todo lo contrario ocurría en su España natal, donde su figura había sido muy desconocida. Sin embargo, en el año 1994, Jerald Green publicó un artículo en la revista Goya de la Fundación Lázaro Galdiano titulado "Federico Castellón: reivindicación para un surrealista español" (Green, 1994), en el que ponía en valor al artista de Alhabia, denunciando el sorprendente desconocimiento de su figura en España. En octubre del mismo año se inauguraba en el Museo Nacional Centro de Arte Reina Sofía la gran exposición titulada «El Surrealismo en España», en la que se incluyeron cuatro obras de Federico. A la muestra acudió su viuda Hilda Greenfield, que donó al Museo la obra «Paisaje surrealista con desnudo y paisaje» [1]. En el catálogo de la exposición se subrayaba que, por muy diversas circunstancias, Federico Castellón era todavía un desconocido en España.

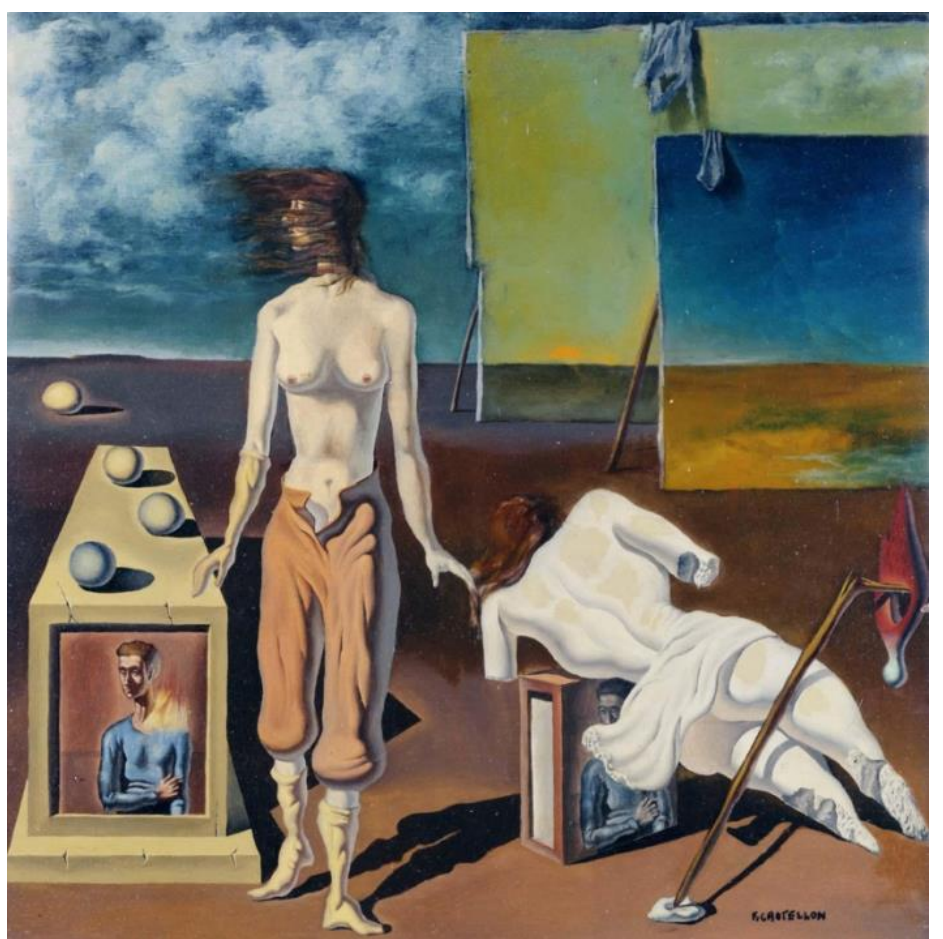

1. Paisaje surrealista con desnudo y paisaje (1938). Federico Castellón. Óleo sobre lienzo. Museo Nacional Centro de Arte Reina Sofía. Madrid

\section{De Almería a Nueva York}

Federico Castellón nace en el pueblo almeriense de Alhabia en 1914. Su familia gozaba de cierta posición; su abuelo, Raimundo Castellón Delgado, había sido uno de los mayores parraleros de la localidad, de la que además fue alcalde por el Partido 
Conservador, cargo que ostentaría más tarde su tío Pedro Castellón Salvador. El desahogo económico de la familia se aseguraba también con la propiedad de una próspera fábrica de curtidos de pieles.

Sus padres, Raimundo Castellón y Josefa Martínez, habían creado una numerosa prole, cuya pervivencia se vio amenazada en un momento dado por los reclutamientos de mozos para la sangrienta Guerra de Marruecos. Según las declaraciones del propio artista (Cummings, 1971, s.p.), esta fue la razón fundamental que provocó la decisión de sus progenitores de emigrar a los Estados Unidos, país al que previamente habían viajado su padre y su tío José. La familia se trasladó en primer lugar a Barcelona, donde vivirán entre 1918 y 1919, ciudad de la que Federico recordaba el ambiente de crispación y violencia, entonces lugar de enfrentamiento del terrorismo anarquista y el "pistolerismo" o terrorismo blanco auspiciado por buena parte de su sector patronal.

Ya en Estados Unidos, la familia se instala en el barrio neoyorquino de Brooklyn. Allí existía una numerosa colonia española, de la que formaban parte algunas familias almerienses. En aquel entorno se creó el Grupo Salmerón, en honor al hijo de Almería que fuera tercer presidente de la Primera República Española y en él también se integraron los Castellón. Aquellos «salmeronianos» realizaron en la distancia numerosas acciones de apoyo a la Segunda República, incluida una manifestación en Washington de las mujeres del grupo para conseguir el apoyo del presidente Roosevelt a la causa republicana (Fuertes, 2008).

En Nueva York, el padre y los hijos mayores comienzan enseguida a trabajar para sacar la familia adelante. Mientras, nuestro artista niño tendrá dificultades para integrarse, especialmente por su desconocimiento del inglés, lo que le llevará a repetir curso en el colegio. Federico se aísla en su mundo interior. Contemplar ensimismado a uno de sus hermanos pintar al pastel le suscita una afición incansable hacia el dibujo, actividad que se convertirá en su principal evasión [2]. 


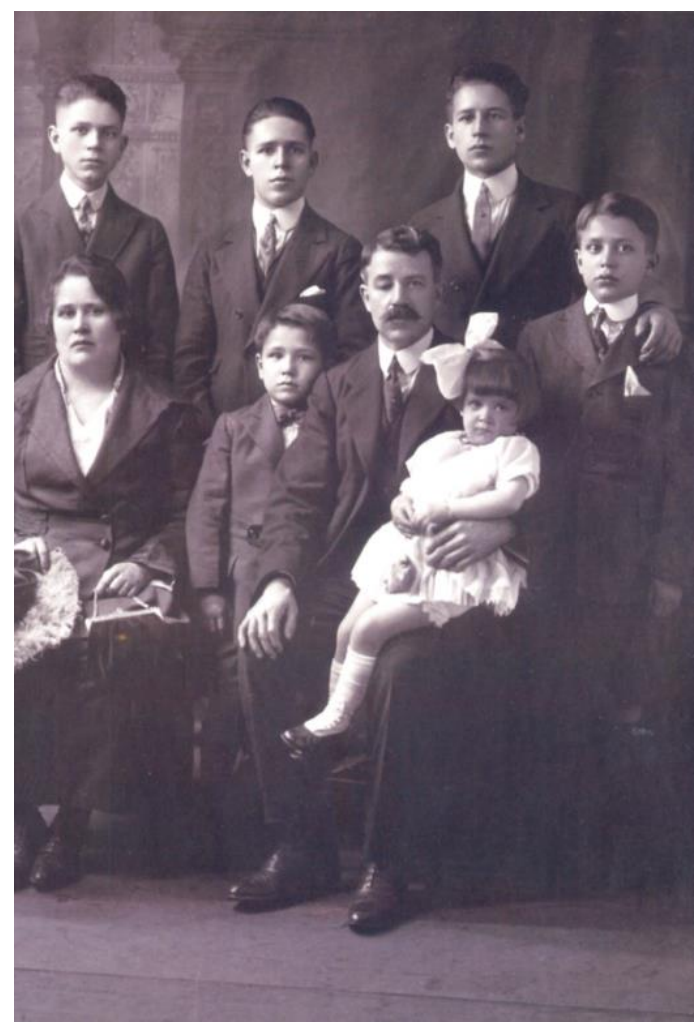

2. Familia de Raimundo Castellón. Federico Castellón en primera fila entre sus padres. Archivo particular de Elisa Castellón

No sin dificultades y con mucho empeño, supera los problemas idiomáticos, al punto de conseguir corregir totalmente su acento, del que hacían bromas sus compañeros y, mejorando su integración, llegará a destacar tempranamente en la educación primaria por sus cualidades artísticas. Esta inclinación al arte será especialmente valorada y potenciada por sus profesores del instituto Erasmus Hall, donde estudiará la educación secundaria. A la par que cursa sus estudios, acude a clases y talleres de arte que, por recomendación de sus profesores complementa con visitas a museos y galerías, que enriquecen su formación. Durante la secundaria también trabajó en una carnicería, y en los veranos en la fábrica de galletas Sunshine, donde trabajaba su padre.

\section{Sus primeros trabajos artísticos}

En 1933, año de su graduación en el instituto, un jovencísimo Federico ha iniciado con ímpetu su carrera artística. Ha pintado murales para particulares y para el propio Erasmus Hall y ha expuesto y vendido sus primeros cuadros. Pero el hecho más relevante para su trayectoria fue conocer al pintor Diego Rivera, que se encontraba en Nueva York en esos momentos con el encargo de realizar los malogrados murales del Rockefeller Center. La 
madre de Federico lo llevó a una conferencia del mejicano y por mediación de un amigo común consiguió que su hijo fuera presentado al muralista. Rivera lo citó posteriormente en su hotel y allí conoció algunas de sus obras que, sorprendido por la precocidad de aquel muchacho, valoró muy positivamente al punto de apadrinar su carrera.

Rivera lo recomendará al Gobierno de la República Española, del que finalmente obtendrá una beca de cuatro años para estudiar en Europa y también lo pondrá en contacto con una figura fundamental para su lanzamiento, el galerista Carl Zigrosser, director de la Galería Weyhe, que acogió con entusiasmo la organización de una exposición del joven Federico, muestra que fue muy valorada por la crítica neoyorquina. Desde ese momento aquella galería seguiría exponiendo y vendiendo su obra hasta finales de 1941.

El comienzo de su viaje a Europa es inicialmente un reencuentro con su tierra a la que llega en el verano de 1934. Federico visita su Alhabia natal, donde pasa unos días con su familia, obsequiando a sus tías maternas con alguna de sus obras. También visita Almería, ciudad en la que la prensa de la época recoge su participación en la Exposición Provincial de Bellas Artes con unas treinta obras (Cortés-Bervel, 1934; Martínez Puertas, 1934; Payá Sanchís y López Suárez, 1934). Su producción, entonces muy variada, pero especialmente surrealista, con gran influencia de Salvador Dalí y Giorgio De Chirico «El regreso del hijo pródigo» (1933) [3], parece que no caló especialmente entre sus paisanos, ya que no recibirá ninguna de las medallas que se otorgaron en aquella muestra. Sin embargo, como señala Juan Manuel Bonet (Bonet, 2008), en esta corta estancia almeriense se incorporan a su pintura muchos elementos de su entorno natal: el árido paisaje, la arquitectura doméstica, la luminosidad «Paisaje de Almería» (1934), elementos a los que se añade el clasicismo mediterráneo, tan presente a lo largo de toda su producción. 


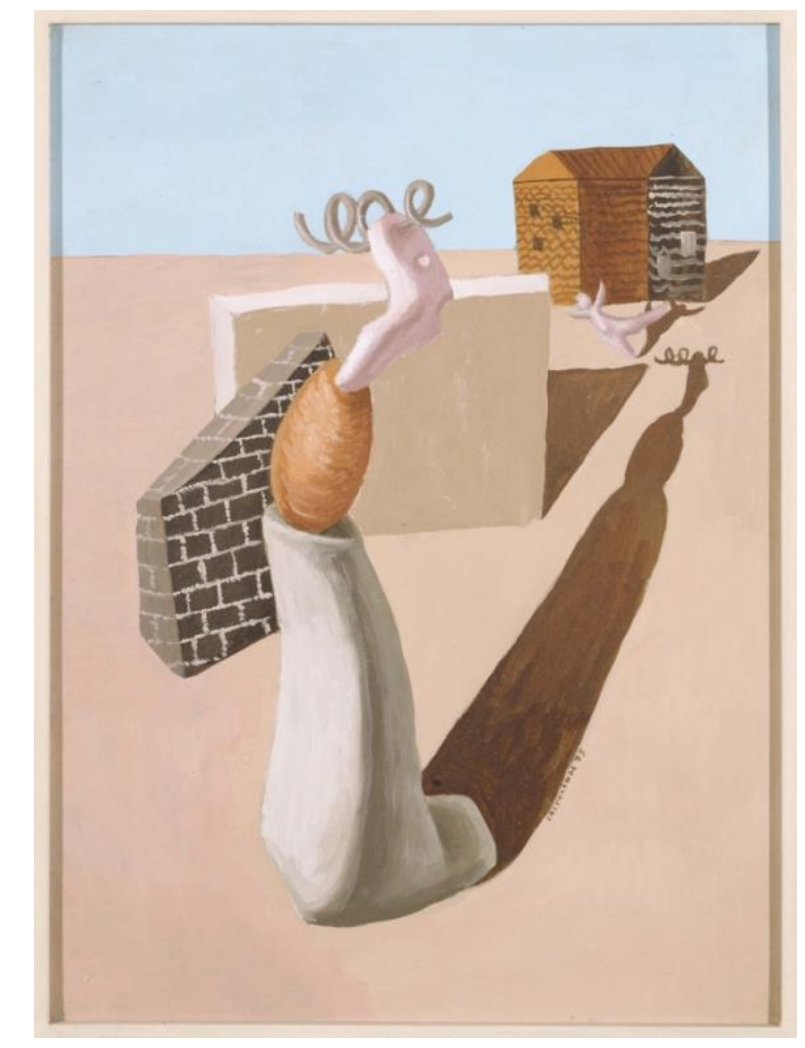

3. El regreso del hijo pródigo (1933). Federico Castellón. Óleo sobre cartón. Museo Nacional Centro de Arte Reina Sofía. Madrid.

Prosigue viaje a Madrid, donde se alojará como becario de la séptima promoción de la Casa de Velázquez. La sede de la institución era un precioso edificio que poco después, al inicio de la Guerra Civil, será totalmente destruido en los bombardeos de la Ciudad Universitaria. Tras el brutal episodio, la institución francesa perdió sus archivos y las obras que los artistas becados solían donar a la casa, no quedando, al margen de su estancia, ningún rastro documental o artístico de Castellón, según la información recabada en la propia institución. En diciembre de 1934, antes de marchar a París, realiza su única exposición en solitario conocida en España, en la madrileña Sociedad de Amigos del Arte. La muestra se compondrá de 65 obras, 50 dibujos y 15 pinturas, combinando distintas técnicas y estilos que abarcaban lo figurativo, el cubismo, el surrealismo e incluso "dibujos al comercial de libros", como se reflejaba en el programa.

En general, la exposición recibe una crítica muy favorable en la prensa. El escritor y crítico de arte Manuel Abril (Abril, 1934) le dedicará una extensa crónica. El artículo se inicia elogiando al hijo de emigrantes que afortunadamente el Gobierno de la República había becado para perfeccionar su formación artística, ensalzando la 
precocidad del pintor que aún no había cumplido veinte años de edad, y especialmente su capacidad de adaptación y dominio de las diferentes técnicas y temáticas tratadas. Abril solo menciona algunas notas negativas en cuanto al óleo, que considera con «menor lirismo que los dibujos». No obstante, el crítico remata su reseña con un acertado vaticinio: «O mucho nos equivocamos, o esta promesa ya en flor, ha de dar frutos auténticos». En otra de las reseñas de la exposición, aparecida en el periódico «La Época» firmada por un tal J.M., se destaca la influencia de Picasso en las obras de Federico, valorando especialmente los paisajes al pastel de líneas cubistas. Coincidiendo con Abril, se califica al artista como una figura todavía muy joven pero dotada de grandes cualidades que le auguraban una gran proyección futura.

La exposición madrileña, especialmente en la parte dedicada al arte comercial, suscitó el interés del pintor y profesor Javier Colmena Solís, corresponsal en España de las prestigiosas revistas de diseño gráfico «The Studio», «Gebrauschsgraphik»y «Commercial Art» que se pone en contacto con Castellón por medio de un «saluda» (Colmena Solis, 1934), en el que solicita su autorización para fotografiar sus obras, con destino a ilustrar un artículo para estas publicaciones.

Una vez en París, el almeriense participa en la importante muestra de artistas españoles organizada por el Colegio de España (1935), en la que el joven artista expone junto a figuras como Francisco Bores, Dalí, Julio González, Joan Miró o Picasso. Durante su estancia entra en contacto con distintas figuras del surrealismo como el propio Dalí, y dedica gran parte de su tiempo a visitar con frecuencia el Museo del Louvre. Federico permanece en la capital francesa hasta 1936, precipitando su retorno a Estados Unidos cierta confusión con su llamada al servicio militar en la que se interrumpía su beca y se le destinaba al Marruecos español.

\section{Litógrafo y Calcógrafo}

De vuelta a América, en 1936 se producen dos grandes momentos en su trayectoria: su participación en otra importante e histórica exposición: «Fantastic Art. Dada and Suarrealism», organizada por el MOMA, y el comienzo de su experimentación con la litografía. 
Esta empatía inicial con el arte gráfico se produce por un lado por sus magníficas cualidades como dibujante, que aplicará con maestría a la litografía, sustituyendo con facilidad el lápiz y el soporte de papel por el lápiz graso y la piedra. Por otro lado, aunque el artista era cada día más valorado, también existía una motivación económica. Castellón, como hemos visto, pertenece a una familia cuyos miembros, con la excepción del apoyo incondicional de su madre, tenían serias dudas sobre su porvenir económico, que dependía en exclusiva de las ventas de sus obras de arte, máxime durante los coletazos de la Gran Depresión. Carl Zigrosser, y especialmente Harry Stemberg, grabador y también hijo de emigrantes, serán los que le animen a estampar sus dibujos dado el beneficio económico que podía sacar a una obra seriada en comparación con la única venta del dibujo original. Tras algún intento fallido, como el mismo relata (Cummings, 1971, s.p.), realiza con éxito su primera estampa litográfica “Cita en el paisaje” en el taller de George Miller. La tirada de 50 ejemplares se agotaría en poco tiempo, reportándole un considerable beneficio económico e incorporando definitivamente el grabado como una de las formas de expresión artística predominantes en su obra futura.

La producción del almeriense de estos años tanto en sus pinturas y dibujos, como en su abundante producción gráfica: «La figura oscura» (1938) [4], «La novia» (1940) o «Entre las barcas» (1941), es cada vez más valorada en los círculos artísticos norteamericanos, y empieza a recibir diversos premios de pintura y de grabado, y becas como la Guggenheim, que se le concederá en dos ocasiones. En la correspondiente a 1940, año en que contrae matrimonio con la también artista Hilda Greenfield, viaja por el Oeste de los Estados Unidos al estar Europa en guerra. Aunque él mismo declarará el escaso impacto de este viaje en su producción artística, en alguna de sus obras, como en «Cita en Taos», se aprecia cierto acercamiento al regionalismo norteamericano. 


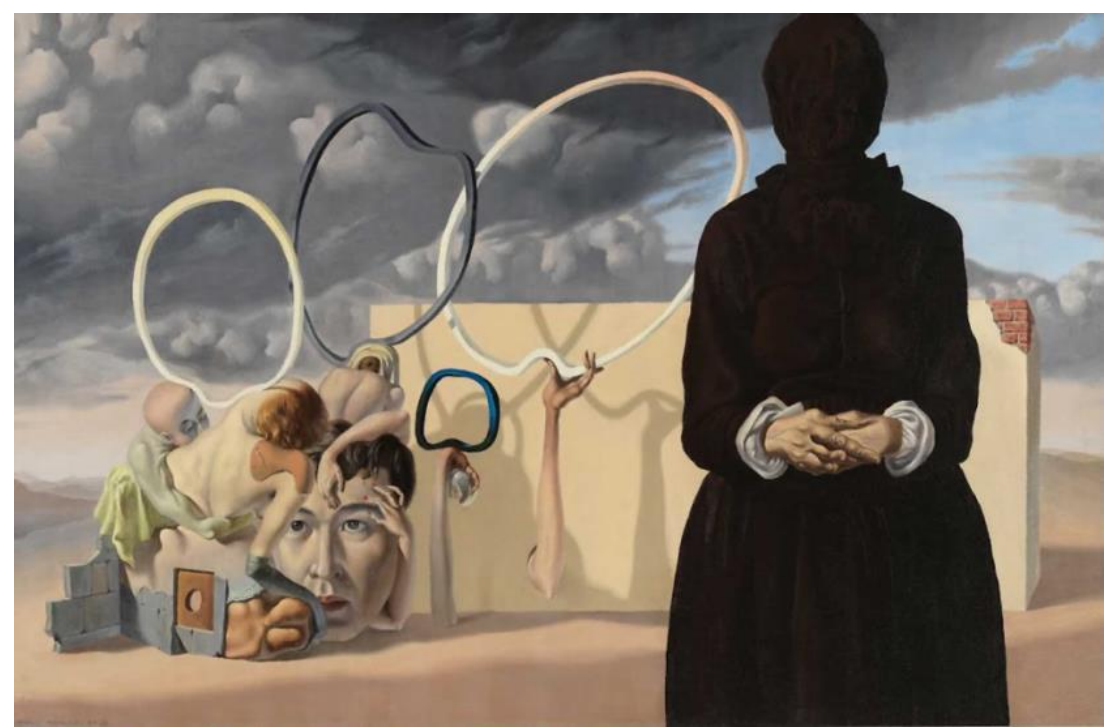

4. La Figura Oscura (1938). Federico Castellón. Óleo sobre lienzo. Whitney Museum of American Art.

New York.

Al comienzo de la década de los 40 se produce un cambio importante en la comercialización de su obra, al abandonar la galería Weyhe, que había entrado en cierto declive al no aceptar obras en consignación, y apostar por la galería de la Asociación de Artistas Americanos (AAA), seducido por su gerente, Louis Lowenthal, y las sustanciosas ganancias que había obtenido con sus primeros encargos en ella (Cummings, 1971).

\section{Del Surrealismo al Expresionismo Figurativo}

Al nacionalizarse estadounidense en 1943, Federico se alista en el ejército con la intención de apoyar a la causa aliada frente al nazismo, probablemente motivado por el origen judío de su esposa, según supone su sobrina Elisa Castellón. En su calidad de dibujante es nombrado sargento técnico. Es ésta una parte cuando menos sorprendente de la vida de Federico ya que, por mediación de su mujer, entrará poco después a formar parte de la O.S.S. (la Oficina de Servicios Estratégicos, antecedente de la C.I.A.), trabajando como fotógrafo y ocupando diversos destinos en Birmania y especialmente en China, trabajos que han suscitado con el paso del tiempo las más diversas interpretaciones (Utrera, 2008). Al margen de sus servicios para la Inteligencia de los Estados Unidos, su estancia en el país asiático será muy fructífera artísticamente, dando lugar tiempo después a la confección de una carpeta de 11 grabados al aguatinta, «China Portfolio», que son una buena muestra del desarrollo que el artista había alcanzado también como calcógrafo. 
Las estampas se presentan con una original asimetría de los formatos, que adapta a representaciones realistas con trasfondo social -aspecto algo inusual en su producción- de escenas del día a día de los habitantes de Kunming, por otra parte, bastante lejanas a las representaciones del orientalismo romántico.

Tal vez su alejamiento de Nueva York por causa de la Segunda Guerra Mundial, al que se añade su evolución hacia el expresionismo figurativo, le distancia de los surrealistas europeos que precisamente habían abandonado el continente por la misma causa y fueron estableciéndose en aquella ciudad desde 1941. Breton, Ernst, Masson, Matta, entre otros, junto a Salvador Dalí, entrarán en contacto con los surrealistas norteamericanos: Baziotes, Matherwell, Pollock, Gorky y Rothko, conformando la llamada Escuela de Nueva York, que será el punto de arranque del expresionismo abstracto (Alix, 1999, p.13).

Entre aquellos artistas emigrados de la Francia ocupada, también había un grupo de artistas españoles. La mayoría de ellos se refugiaron en Méjico, pero algunos como Esteban Francés y Eugenio Granell lo hicieron en Nueva York. Los dos, junto a Federico Castellón, conforman un pequeño núcleo surrealista español en la Gran Manzana, que al igual que el resto de los surrealistas europeos vendría a cambiar "la trayectoria del arte americano de su tiempo" (García de Carpi, 1994, p.41).

Federico no perteneció a ningún colectivo artístico, lo cual no implicó que mantuviera amistad con numerosos artistas entre los que se encontraban: Chaim Gross, Antonio Frasconi, Jack Levine, Adolf Dehn, James Leshay, Harry Sternberg, Alexander Dubkin o Sol Wilson (Freundlich, 1978, p.15). Con algunos compartía el haber nacido en un país extranjero, también muchos de ellos se dedicaban como él a la ilustración y al arte gráfico, especialmente a la litografía y, además, en un momento dado, sus estudios estuvieron ubicados en el mismo barrio de Nueva York. El carácter abierto y vital del almeriense y su pasión por la música y la lectura, especialmente la psicología y el psicoanálisis, le predisponían a interminables tertulias con estos y otros colegas, largas charlas sobre muy distintos temas que vinieron a hacerse costumbre a lo largo de toda su vida.

Tras la Segunda Guerra Mundial se inicia la faceta docente de Federico Castellón, que ejercerá su magisterio en las universidades de Columbia, Siracusa, The New School 
y el Instituto Pratt. En estos años, y seguramente sin él saberlo, ya que se recurrió a alguna obra en poder de la familia -quizás aquellas que regaló a sus tías en su visita de 1934- se le incluye en la exposición que sobre el Movimiento Indaliano se celebró en el Círculo Mercantil de Almería en 1946 y en la organizada después en Madrid por Eugenio D’ors, aunque en esta se expondría sólo su «Paisaje de Almería». Su inclusión en la distancia a aquel movimiento artístico almeriense, encontraba básicamente su justificación en la incorporación de los elementos del paisaje mediterráneo y almeriense en su obra (Utrera, 2011, pp.354-356).

Desde la década de los 40 y especialmente entre 1950 y 1957, Castellón se dedica a la ilustración. El artista había adquirido una nueva casa en Brooklyn y necesitaba incrementar sus ingresos. En esta vertiente artística realiza diversos trabajos para la revista Life y para numerosos libros, faceta de la que encontramos una espléndida y completa colección en el Museo de la Fundación Casa Ibáñez de la localidad almeriense de Olula del Río. Él mismo justificaría su dedicación a esta vertiente artística más comercial por necesidades económicas, ya que no podía afrontar nuevos gastos solo con la venta de su obra en galerías.

Como ya comentamos, en 1950 obtendrá su segunda beca Guggenheim, que en esta ocasión empleará en viajar a Italia, realizando varias composiciones de tema mitológico, que tanto trató a lo largo de su producción, como «Leda y el Cisne», «Acteón y Diana» o «El juicio de Paris». Su estilo guardaba ya poca relación con el surrealismo de los 30 y los 40, decantándose cada vez más hacia un surrealismo con un sello absolutamente personal alejado de lo daliniano, en el que primaba lo simbólico, adentrándose en el expresionismo figurativo.

Entre 1961 y 1963, Castellón reside en Europa, entre Italia, Paris y Madrid, en algunas ocasiones solo y en otras acompañado por su mujer y su hijo Paul. De estas estancias y de otras de años posteriores, el propio artista da cumplida información en una extensa colección de cartas a familiares y amigos que se conservan en el Smithsonian Institute. Esta abundante documentación, que está siendo estudiada por su sobrina Elisa Castellón, está proporcionando datos, desconocidos hasta ahora, fundamentales para completar su biografía. En este sentido, sobre estos años de estancia en España, una de sus cartas nos revela su relación con el grabador griego asentado en Madrid, Dimitri 
Papageorguiu, en cuyos talleres Federico se planteó trabajar, según él mismo anunciaba, dado lo económico de sus precios en comparación con Desjobert en Paris, y la buena calidad de sus estampaciones (Castellón, 1962). Parece finalmente que el almeriense podría haber llegado a grabar en el establecimiento madrileño ya que en la colección del taller de Dimitri depositada en el Museo Provincial de Jaén hemos encontrado la litografía a dos colores «El suplicante», fechada en este mismo año.

En otra carta posterior desde Paris a su mujer y su hijo en diciembre de 1966 (Castellón, 1966), se deduce por la fecha que Federico está trabajando en la carpeta «Seis grabados» que realizará al aguafuerte y aguatinta. El artista describe como transcurren sus extenuantes jornadas de trabajo en el taller de Roger Lacourriere, y también comenta sus ratos libres, que dedicaba bien recorriendo librerías de viejo y mercadillos a la búsqueda de grabados, carteles y afiches, que luego revendía en los Estados Unidos, bien dedicados a adquirir materiales para sus estampaciones en la antigua casa Charbonnel. De sus comentarios sobre los tipos de tintas, rodillos y papeles más adecuados se deducen sus amplios conocimientos técnicos de grabado y el proceder sumamente meticuloso que se descubre en sus estampaciones.

En 1969 se publica el relato de Edgar Allan Poe «La máscara de la muerte roja», para la que Federico realiza en Desjobert 16 litografías a color de excelente factura, destinadas a acompañar una cuidada edición de bibliófilo (Poe y Castellón, 1969) [5]. En esta serie se aprecian especialmente las influencias de Poe y de Goya en su producción: la representación con imágenes oscuras de condiciones humanas como la angustia, el dolor y el miedo, envueltas en elementos fantásticos y oníricos. Este paralelismo ha dado lugar a estudios y exposiciones en los Estados Unidos, como la denominada «Miedo y locura: las impresiones visionarias de Francisco Goya y Federico Castellón», con 38 grabados de ambos artistas, realizada por el Kalamazoo Institute of the Arts de Michigan, que ha sido expuesta en varios estados norteamericanos. 


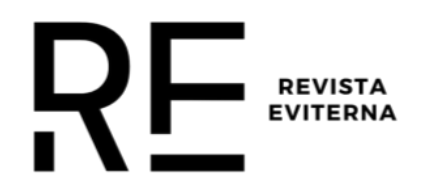

\section{REVISTA CHILENO-ESPAÑOLA, ACADÉMICO CIENTÍFICA DE HUMANIDADES, ARTE Y CULTURA (ISSN: ISSN: 2530-6014), NÚM. 7 (SEPTIEMBRE 2020)}

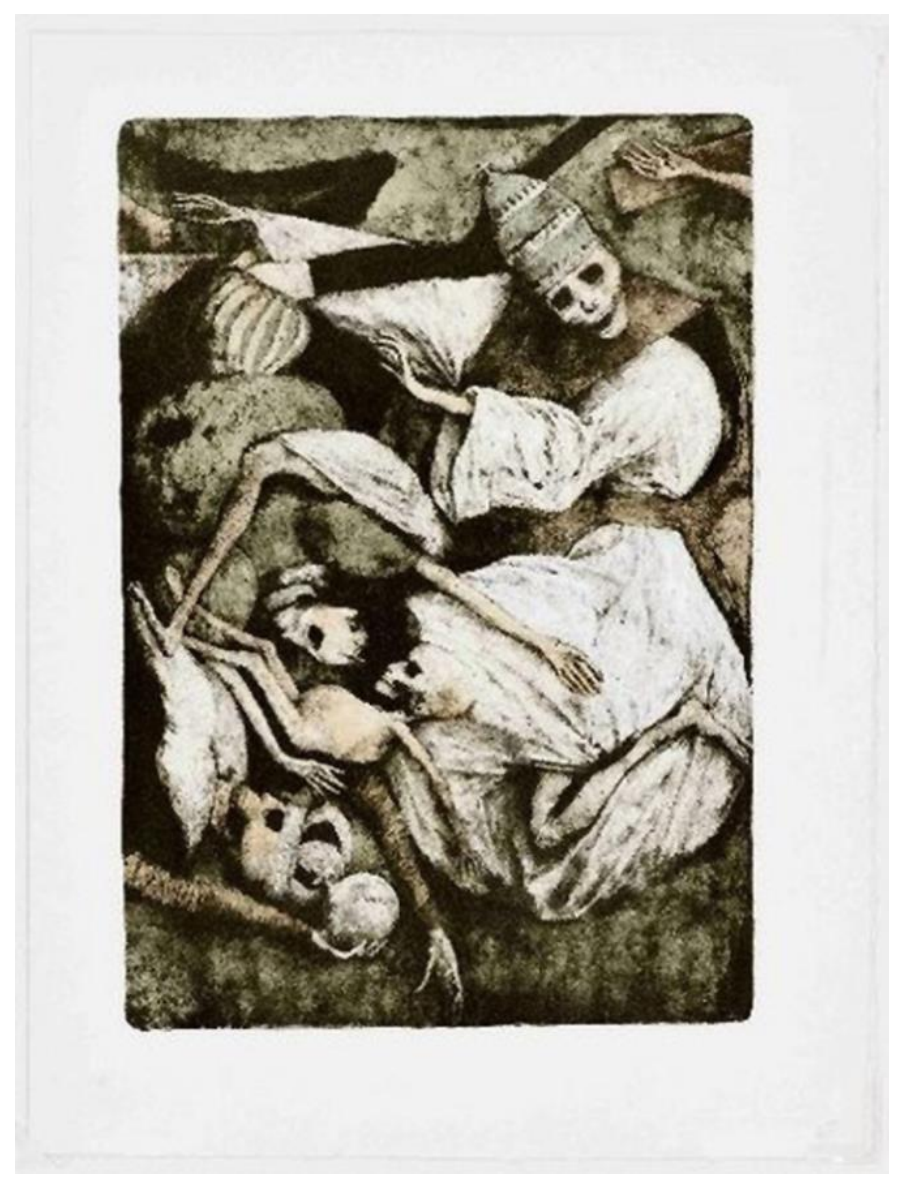

5. La máscara de la muerte roja (1969). Federico Castellón. Litografía. Colección particular.

Una de las últimas carpetas de grabados, que Federico Castellón realizará entre 1969 y 1971, será el «Alfabeto erótico», serie en la que nos muestra ese erotismo fantástico, onírico, de carácter morboso y con cierto tono sarcástico, que impregna su obra desde la mediación del siglo. Será un trabajo conjunto con Peter Paone, íntimo amigo de nuestro artista con el que había coincidido en el Instituto Pratt. Cada grabador realizó 13 letras para la edición normal compuesta por 26 grabados, y un autorretrato para la edición de lujo. Desgraciadamente Castellón fallecería antes de ver la edición completamente acabada. 


\section{FEDERICO CASTELLÓN Y SU RECONOCIMIENTO EN ESPAÑA [6]}

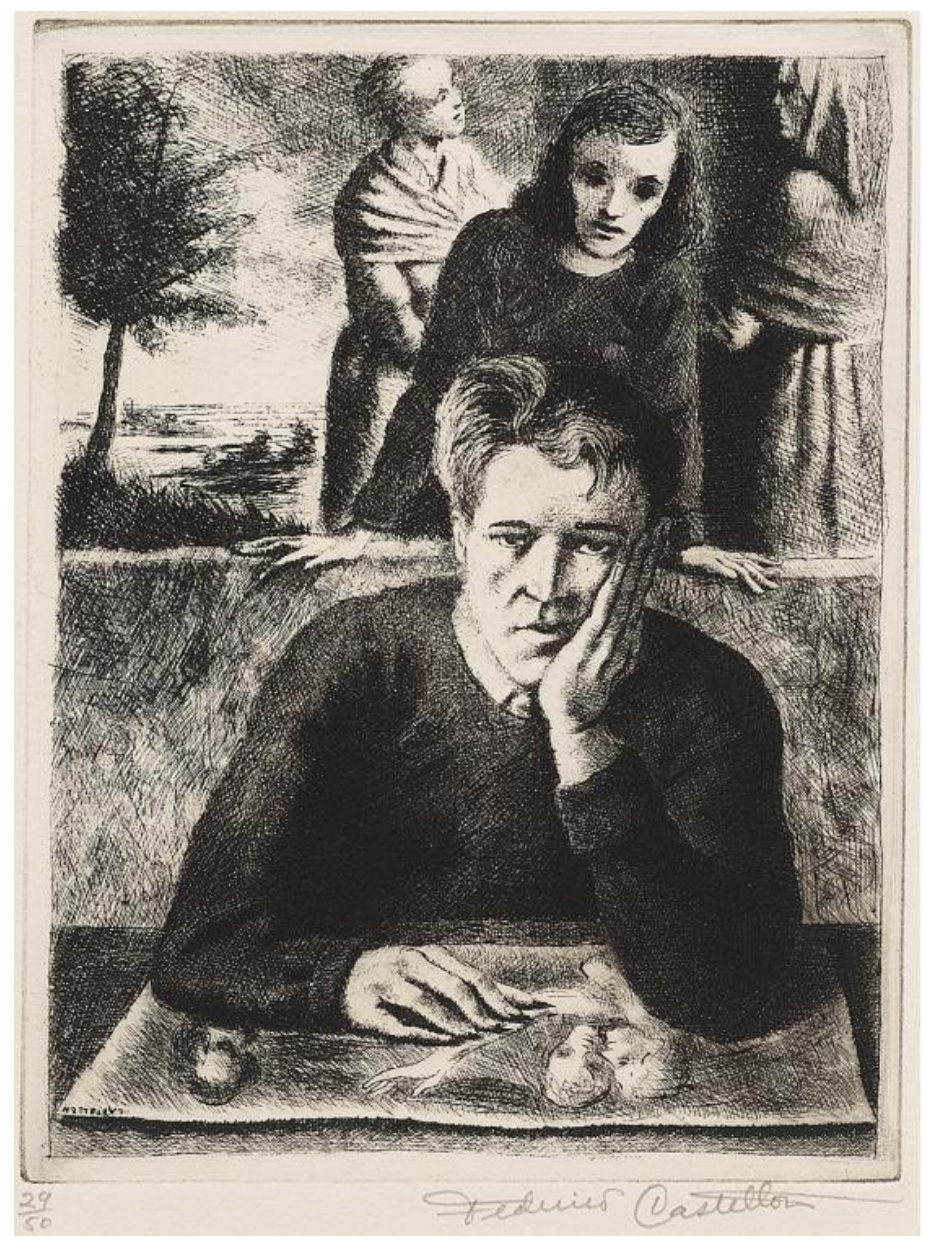

6. Autorretrato con H (1942). Federico Castellón. Grabado al aguafuerte. Galería Nacional de Retratos, Instituto Smithsonian. Washington

Ante el desconocimiento generalizado en nuestro país de su figura artística, parece que el año 1994 marcó un punto de inflexión en la consideración por la Historia del Arte española de Federico Castellón con su inclusión en la exposición del surrealismo español del Reina Sofía. Diez años después, la misma institución volvería a exponer su obra en la muestra «Huellas Dalinianas».

Pero especialmente en su tierra natal el pintor nunca fue olvidado. Y a aquellas exposiciones del Movimiento Indaliano, se unirán numerosas iniciativas que lo consagran como «profeta en su tierra».

En 2008, la Consejería de Cultura de la Junta de Andalucía organizaría en el Museo Arqueológico de Almería una excelente exposición monográfica de su producción titulada «Federico Castellón: De Almería a Nueva York», a la que en años posteriores le 
han sucedido otras muestras organizadas por instituciones públicas y privadas. También en aquella ciudad se han editado varias publicaciones en castellano sobre su obra (Fernández de Capel Baños, 2006 y 2009; Martínez Martín, 2012; Martín Robles, 2012 y 2016), en la que se han especializado la Galería Acanto y el ya citado Museo de la Fundación Casa Ibáñez de la pequeña localidad de Olula del Río, donde se conserva un fondo sorprendente en cuanto a calidad y cantidad del hispano-norteamericano.

No se podría acabar este artículo sin mencionar que el reconocimiento contemporáneo de Federico Castellón en Almería se debe en buena medida a su sobrina Elisa Castellón, entusiasta seguidora de la figura humana y artística de nuestro genio. Elisa ha impulsado y apoyado con sus conocimientos y su colección particular casi la totalidad de las iniciativas culturales que en aquella provincia se han realizado a lo largo de estos años. A ella se debe también la redacción de este artículo.

\section{Recursos bibliográficos}

Abril, Manuel (1934), Artes plásticas. Nuevo español y nuevo artista. Recorte de prensa sin cabecera. Archivo de Dionisio Godoy. Dossier Federico Castellón. Almería

Alix, Josefina et al (1999), Surrealistas en el exilio y los inicios de la Escuela de Nueva York. Museo Nacional Centro de Arte Reina Sofía: Madrid.

Barr, Alfred H., (Ed.) (1936), Fantastic art, dada, surrealism. The Museum of Modern Art: NewYork.

Bonet, Juan Manuel (2008), Federico Castellón. Notas para un retrato, en CARINI, Miguel (Dir.). Federico Castellón, de Almería a Nueva York (pp.27-38). Consejería de Cultura de la Junta de Andalucía: Almería.

Carini, Miguel (Dir.) (2008), Federico Castellón, de Almería a Nueva York. Consejería de Cultura de la Junta de Andalucía: Almería.

Castellón, Federico (1962), “Carta a Adolph Dehn”, Madrid, 8 de febrero de 1962, en Federico Castellon, papers, 1935-1967. Archives of American Art Smithsonian Institute. Washington. 
Castellón, Federico (1966), “Carta a Hilda y Paul Castellón” Paris, 30 de diciembre de 1966 en Federico Castellon, papers, 1935-1967. Archives of American Art Smithsonian Institute. Washington.

Colmena Solís, Javier (1934), “Saluda a Federico Castellón”. Madrid, 29 de diciembre de 1934, Archivo de Dionisio Godoy. Dossier Federico Castellón. Almería

Cortés-Bervel, Manuel (18 de agosto de 1934), Valores Almerienses, Diario de Almería, p.1.

Cummings, Paul (1971), "Oral history interview with Federico Castellon", Abr.7-1971 Abr.14" Archives of American Art Smithsonian Institute: Washington. Recuperado de: https://www.aaa.si.edu/collections/interviews/oral-history-interview-federico-castellon5452\#transcript

Fernández de Capel Baños, María del Carmen (2006), Federico Castellón. Análisis de las litografías. Instituto de Estudios Almerienses: Almería.

Fernández de Capel Baños, María del Carmen (2009), Vanguardias de la Pintura almeriense y su presencia internacional. Consejería de Cultura de la Junta de Andalucía, y Ayuntamiento de Roquetas de Mar: Almería.

Freundich, August L. (1978), Federico Castellón. His Graphic Works 1936 -1971. Syracuse University: Syracuse, New York.

Fuertes, Guillermo (15 de abril de 2008), Las mujeres del Grupo Salmerón, La Voz de Almería, p.64.

García de Carpi, Lucía (1994), La Respuesta Española, en VV.AA. El surrealismo en España 1924-1939 (pp.21-44) Museo Nacional Centro de Arte Reina Sofía: Madrid.

Green, Jerald R. (1994), Federico Castellón: reivindicación para un surrealista español, Revista de Arte Goya, n²40 (pp. 349-354). Museo Lázaro Galdiano: Madrid.

J.M. (25 de diciembre de 1934), Notas de Arte. Exposición Federico Castellón, La Época, p. 5.

Martín Robles, Juan Manuel (2016), Federico Castellón. La colección del artista. Fundación Museo Casa Ibáñez: Almería. 
Martín Robles, Juan Manuel (2012), Federico Castellón. Las series eróticas. Fundación Museo Casa Ibáñez: Almería.

Martinez Marín, Ana (2012), Federico Castellón, un Lenguaje Propio. Fundación Museo Casa Ibáñez - Centro de Arte Museo de Almería - Fundación Caja Mar - estudio-53: Almería.

Martínez Puertas, José (29 de agosto de 1934), Criticas de Arte. Exposición Provincial de Bellas Artes, Diario de Almería, p.1.

Payá Sanchís, Francisco y López Suárez, Juan (5 de septiembre de 1934), Exposición Provincial de Bellas Artes y Artes Industriales, Diario de Almería, p.1.

Poe, Edgar A. y Castellón, Federico (1969), The Mask of the Red Death. A fantasy by Edgar A. Poe. With sixteen lithographs by Federico Castellón. Aquarius Press: Baltimore.

Utrera, Federico (13 de abril de 2008), El espía que vino del Sur. Cuentos de Colombine. La voz de Almería, p.42.

Utrera, Federico (2011), Cordel de extraviados (Literatura y Arte) 1989-2009. Cabildo de Gran Canaria: Gran Canaria.

Zigrosser, Carl (1950), Introducción, en Castellón, F. China Portfolio. s.p. s.l. 